\title{
Design and control of an ethyl acetate process: coupled reactor/column configuration
}

\author{
I-Lung Chien ${ }^{\mathrm{a}, *}$, Yao-Pin Teng ${ }^{\mathrm{a}}$, Hsiao-Ping Huang ${ }^{\mathrm{b}}$, Yeong Tarng Tang ${ }^{\mathrm{b}}$ \\ ${ }^{a}$ Department of Chemical Engineering, National Taiwan University of Science and Technology, 43, Keelung Road, Sec. 4, Taipei 106, Taiwan, ROC \\ b Department of Chemical Engineering, National Taiwan University, 1 Roosevelt Road, Sec. 4, Taipei 106, Taiwan, ROC
}

Received 6 January 2004; received in revised form 1 June 2004; accepted 8 July 2004

\begin{abstract}
In this paper, design and control of a realistic coupled reactor/column process to produce ethyl acetate is studied. The process design is more complicated because the ethyl acetate product is neither the lightest nor the heaviest component in the system. A search procedure is proposed to obtain the optimum process design and operating condition of this process. The optimum process design is the one that minimize the Total Annual Cost (TAC) of this process while satisfying the stringent product impurity specifications. The optimum overall process design includes a continuous-stirred tank reactor (CSTR) coupled with a rectifier, a decanter, another stripper, and a recycle stream. After the process design is established, the next step is to use dynamic simulation to test the appropriate control strategy for this process. Sensitivity analysis is performed to obtain the suitable temperature control points for the columns. The proposed control strategy is very simple containing only one temperature control loop in each column. This recommended simpler control strategy uses the ratio of acetic acid feed rate to ethanol feed rate to control the 5th stage temperature of the rectifier and uses the stripper reboiler duty to control the 5th stage temperature of the stripper. The proposed control strategy does not need any on-line composition measurements and can properly hold product purity in spite of feed flow rate and feed composition disturbances. For small deviations of the product impurity compositions during disturbances, a slow cascade outer composition loop structure can be implemented using off-line composition measurements from the quality lab.
\end{abstract}

(C) 2004 Elsevier Ltd. All rights reserved.

Keywords: Ethyl acetate process; Coupled reactor/column; Process design; Plant-wide control

\section{Introduction}

Ethyl acetate is an important organic solvent widely used in the production of varnishes, ink, synthetic resins, and adhesive agents. Ethyl acetate (EtAc) is normally produced via reversible reaction of acetic acid (HAc) with ethanol $(\mathrm{EtOH})$. There are only a few papers in the literature on the subject of the production of ethyl acetate via reactive distillation. For steady-state simulation of ethyl acetate reactive distillation column, Chang and Seader [1] used homotopy-continuation method to

\footnotetext{
${ }^{*}$ Corresponding author. Tel.: +886 2 27376652; fax: +886 2 27376644.

E-mail address: chien@ch.ntust.edu.tw (I-L. Chien).
}

solve the steady-state simulation on an ethyl acetate reactive distillation column. Simandl and Svrcek [2] instead used inside-outside method for the steady-state simulation. For dynamic simulation, Alejski and Duprat [3] formulated a dynamic mathematical model of a reactive distillation and validated the accuracy of the simplified model via experimental data. All of the above simulations did not obtain high-purity ethyl acetate product and did not consider the possible liquid-liquid equilibrium in the system.

For the process design of this system with reactive distillation column, Keyes [4] was, perhaps, the first reported paper on an ethyl acetate process using a reactive distillation column in combination with a pre-esterification reactor, two recovery columns, and a decanter. His 
process is quite complex and contains quite a few process equipments. Bock et al. [5] designed an uncatalyzed ethyl acetate process with excess ethanol containing a reactive distillation column and a pressurized recovery column. Although high-purity ethyl acetate product can be obtained from the bottom of the recovery column, the top product containing EtOH/EtAc/ $\mathrm{H}_{2} \mathrm{O}$ has to be recycled back to the reactive distillation column, and, the bottom of the reactive distillation column containing EtOH$/ \mathrm{H}_{2} \mathrm{O}$ which needs further treatment. Vora and Daoutidis [6] studied the operation and control of a single reactive distillation column. The top product is not pure enough, and also the bottom product stream contains all four components in the system. Thus, it will be very difficult for further treatment of the bottom stream. Recently, Tang et al. [7] proposed an overall optimum design of ethyl acetate reactive distillation system. Their overall design includes two columns (one reactive distillation column and a second stripping column), one decanter, and two recycle streams.

In this paper, an alternative process design other than the reactive distillation column is used to produce ethyl acetate. A coupled reactor/column configuration will be explored. The principal behind the coupled reactor/column system, similar to reactive distillation, is that the continuous removal of products from the reaction mixture by distillation reduces the backward reaction rate. The advantages of the coupled reactor/column configuration over reactive distillation column according to $\mathrm{Yi}$ and Luyben [8] include: the existing reactor and distillation column in the plant can be retrofitted for this usage, easy catalyst replacement, and larger reactor holdup can easily be designed, etc. In a three-paper series by Yi and Luyben [8-10], they studied the design and control of various coupled reactor/column systems. The studied systems include: a binary reactor/rectifier, a binary reactor/stripper, a multicomponent reactor/rectifier, a multicomponent reactor/rectifier/stripper, and a more complex process that consists of a coupled reactor/stripper, two distillation columns and one recycle stream. Their studied systems are very simple, ideal chemical systems and also no liquid-liquid equilibrium is considered. Chiang et al. [11] studied a coupled reactor/column system for the production of amyl acetate. Their process is much simpler than the ethyl acetate process because amyl acetate has the highest boiling point in the system. Their system with the configuration of reactor/rectifier/ stripper produces amyl acetate from the bottom of the stripper and also produces water through aqueous phase of a decanter.

In the case of ethyl acetate production, the complete process configuration will need to be more complex because the ethyl acetate and water products are neither the lightest nor the heaviest component in the system. Burkett and Rossiter [12] studied the control strategy of a reactive distillation column with the reaction occurred at the base of a distillation column which is similar to the coupled reactor/column system that will be investigated in this paper. In their system, the top vapor of the column after condensation separates into two liquid phases with the organic phase as the ethyl acetate product. However, the composition of the ethyl acetate product is not pure enough for industrial usage and also no detailed design condition or detailed control study is given in their paper.

The organization of this paper is as follows. The optimum design of a complete coupled reactor/column system will be proposed in Section 2. A search procedure will be given to obtain the optimum process design and operating condition of this process. The control strategy development of this process will be presented in Section 3. Sensitivity analysis is performed to obtain the suitable temperature control points inside the column. Closed-loop dynamic simulation will be used to evaluate the performance of the proposed control strategy. The proposed control strategy needs to hold product purity despite feed flow rate and feed composition disturbances. Some concluding remarks will be given in Section 4.

\section{Optimum process design and operating condition}

\subsection{Conceptual design of the overall coupled reactorl column system}

The thermodynamic model used in this study is the same as the one in Tang et al. [7]. A suitable NTRL (nonrandom two-liquid) model parameter set has been established with excellent prediction of the compositions and temperatures for the four azeotropes in this system. Vapor association of acetic acid due to dimerization has also been included by using the second virial coefficient of Hayden-O'Connell model [13] for the vapor phase. The predicted four azeotropes in this system include three homogeneous azeotropes of EtOH-EtAc, EtOH$\mathrm{H}_{2} \mathrm{O}$, and EtOH-EtAc- $\mathrm{H}_{2} \mathrm{O}$ and also one heterogeneous azeotrope of EtAc- $\mathrm{H}_{2} \mathrm{O}$. The computed azeotropic compositions and temperatures agree very well with the experimental data in the open literature. This thermodynamic model set also predicted all binary VLE and all ternary LLE very well in comparison with the experimental data. The residue curve maps of threecomponent HAc-EtAc- $\mathrm{H}_{2} \mathrm{O}$ and also EtOH-EtAc$\mathrm{H}_{2} \mathrm{O}$ are shown in Figs. 1 and 2.

From Figs. 1 and 2, the highest boiling point temperature of the whole system including the pure components and azeotropes is the acetic acid (HAc) at 118.01 ${ }^{\circ} \mathrm{C}$ and the lowest temperature of the whole system is the EtOH-EtAc- $\mathrm{H}_{2} \mathrm{O}$ three-component azeotrope at $70.09^{\circ} \mathrm{C}$. The next lowest temperature of the whole system is the heterogeneous EtAc- $\mathrm{H}_{2} \mathrm{O}$ two-component 


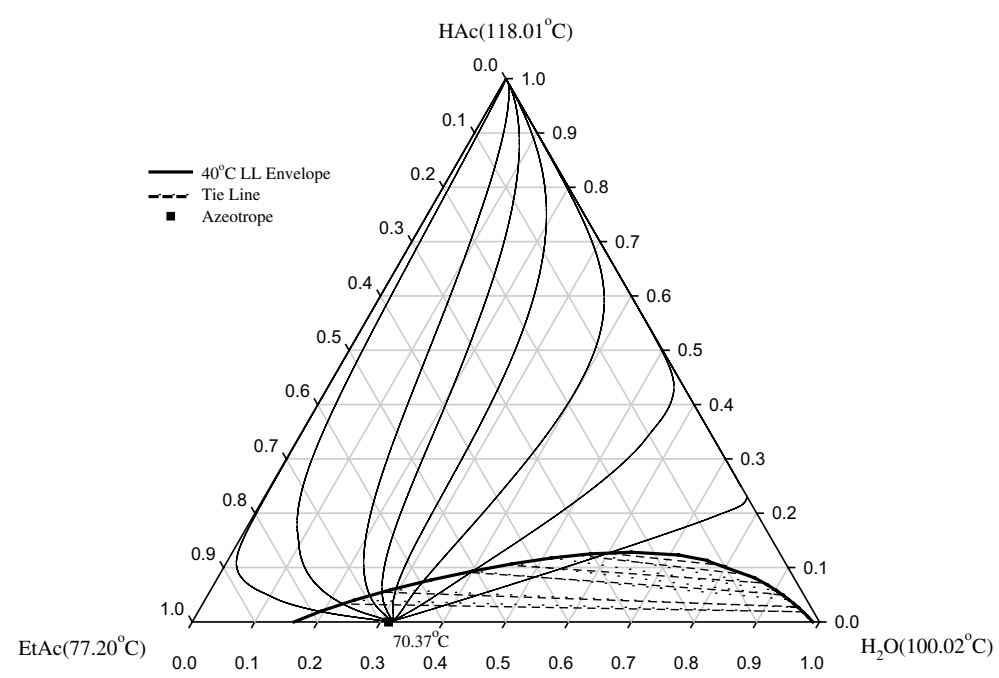

Fig. 1. Residue curve map of $\mathrm{HAc}$ EtAc- $\mathrm{H}_{2} \mathrm{O}$ system.

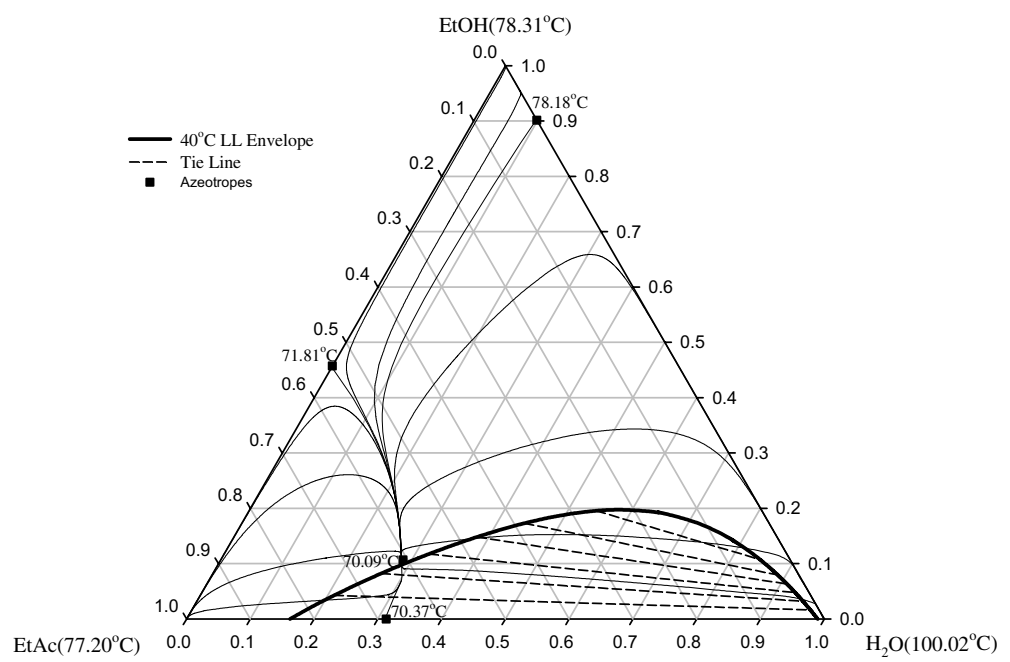

Fig. 2. Residue curve map of EtOH-EtAc- $\mathrm{H}_{2} \mathrm{O}$ system.

azeotrope at $70.37{ }^{\circ} \mathrm{C}$. The proposed coupled reactor/ column system is designed to let most of the reaction occurred in a CSTR with heat input to vaporize the CSTR product into vapor phase. The vapor product is continuously drawn off from the CSTR in order to promote the forward reaction further. The vapor product is fed into the bottom of a rectifier (without heat source) for further separation. The bottom liquid product from the rectifier is designed to have mostly HAc so that it can be returned back to CSTR for reaction purpose. The top vapor from this rectifier is ideally to have top temperature somewhere between the two lowest temperatures $\left(70.09\right.$ and $\left.70.37^{\circ} \mathrm{C}\right)$ of the whole system and also to ensure this mixture after condensation to be inside the two-liquid-phase boundary. This mixture after sub-cooling to $40{ }^{\circ} \mathrm{C}$ can be naturally separated inside a decanter to form organic phase and aqueous phase.
From Fig. 2, the water purity of aqueous phase should be quite high, thus is suitable for discharge. The EtAc composition in the organic phase, although quite high, still does not meet the high purity specification of the final EtAc product. The organic phase composition by natural liquid-liquid separation has the benefit of crossing the distillation boundary into a desirable region to obtain pure ethyl acetate product. This organic phase stream is partly refluxed and is partly designed to feed into another stripper with reboiler for further purification into the final EtAc product. The bottom stream of this stripper should have very high EtAc product purity. The top vapor of this stripper with composition near the top vapor of the rectifier is also condensed and then fed into the decanter. In order to ensure that the mixed feed composition into the decanter is well inside the two-liquid-phase boundary; additional 


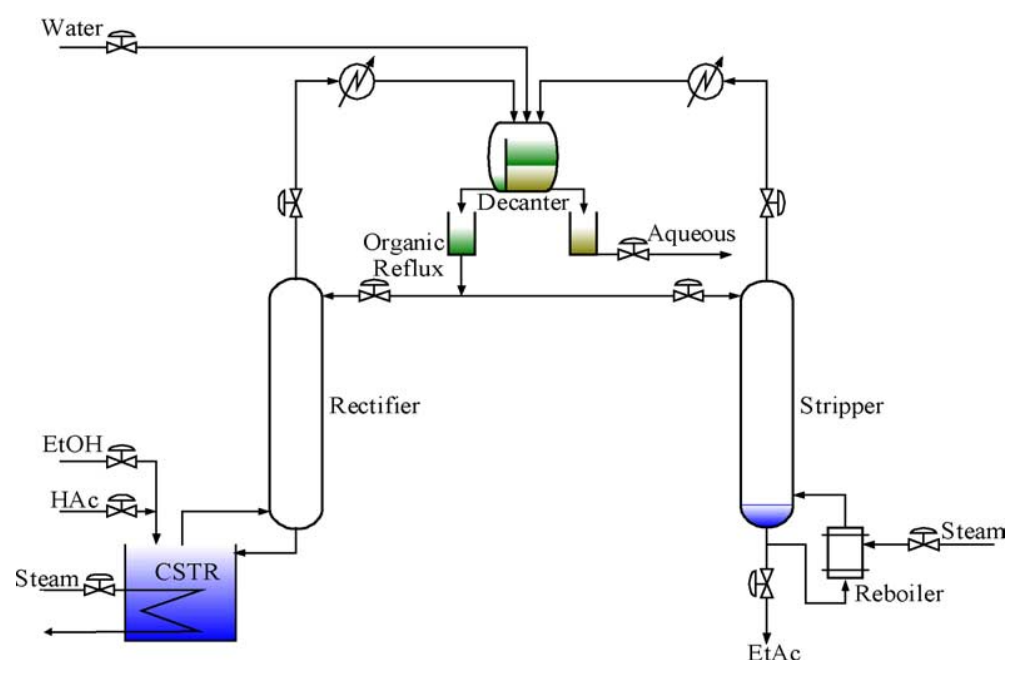

Fig. 3. The proposed design of this system.

water stream may also be injected into the decanter. The proposed design of this overall coupled reactor/column system is presented in Fig. 3.

\subsection{Optimum design flowsheet}

The kinetic model for this chemical reaction system is from the paper by Alejski and Duprat [3] and later used by Tang et al. [7]. One set of the kinetic parameters which will be used only in the CSTR reactor is for the situation with sulphuric acid as homogeneous catalyst and the second set of kinetic parameters which will be used in each stage of the rectifier is for the situation without catalyst.

The above coupled reactor/rectifying column system can be simulated via Aspen Plus ${ }^{\circledR}$ with CSTR as the bottom holdup of a distillation column with thermosyphon reboiler. For this reason, the reboiler duty will not be a degree of freedom in the steady-state simulation. It will be used to specify an extremely small bottom flow rate (e.g., $10^{-6} \mathrm{~g} \mathrm{~mol} / \mathrm{min}$ is used in the simulation) to mimic real situation with no liquid draw from the CSTR. Another two degree of freedoms in the overall system will be used to specify the compositions of the HAc and EtOH impurities in the final EtAc product. The HAc composition in the final product stream is set to be $0.01 \mathrm{wt}^{\%} \%$ by varying the organic reflux flow rate. The EtOH composition in the final product stream is set to be $0.2 \mathrm{wt} \%$ by varying the reboiler duty of the stripper. This stringent product impurity specification is set in accordance with the industrial requirement.

The remaining design variables which can be specified in the optimization study are: the CSTR holdup, the total number of stages of the rectifier, and the total number of stages of the stripper. The remaining operating variables which can be specified in the optimization study are: fresh HAc feed flow rate, and the water injec- tion rate into the decanter. The fresh EtOH feed flow rate will be used to set the base flow rate of this overall system. It is set at $411.9 \mathrm{~g} \mathrm{~mol} / \mathrm{min}$, the same flow rate as in Vora and Daoutidis [6].

The overall search algorithm for the optimum design and operating variables has quite large dimensions. In order to avoid using more complicated mixed-integer nonlinear programming technique combining with this complex rigorous nonlinear process model, a much simpler but may be less efficient exhaustive search procedure is used in this paper. The procedure for the optimization search can be seen in Fig. 4. Total Annual Cost (TAC) of this overall system is used as an objective function for the optimization search. The calculation of the TAC follows the same equations as in Chiang et al. [11] with conservative estimation of the overall tray efficiency for both columns in the system to be $50 \%$. In the CSTR, the price correction factor for the shell material is assumed to be more than twice of the price of materials in the two columns (rectifier and stripper) for corrosion prevention purpose. From the flowchart in Fig. 4, the optimized process design condition can be obtained for each fixed fresh HAc feed rate. Combining all results for each fixed fresh HAc feed rate, the final minimized TAC process design condition can be obtained. The optimum process design condition is shown in Table 1 .

\subsection{Some observations of this optimum design flowsheet}

Comparing this optimum process design condition to the one using reactive distillation in the paper by Tang et al. [7], several observations can be made. The first one is that the number of stages in the reactive distillation column (total of 29 stages) in Tang et al. [7] is much greater than the number of stages in the rectifier in this paper. The reason for large number of stages in the reactive distillation column in Tang et al. [7] is to provide en- 


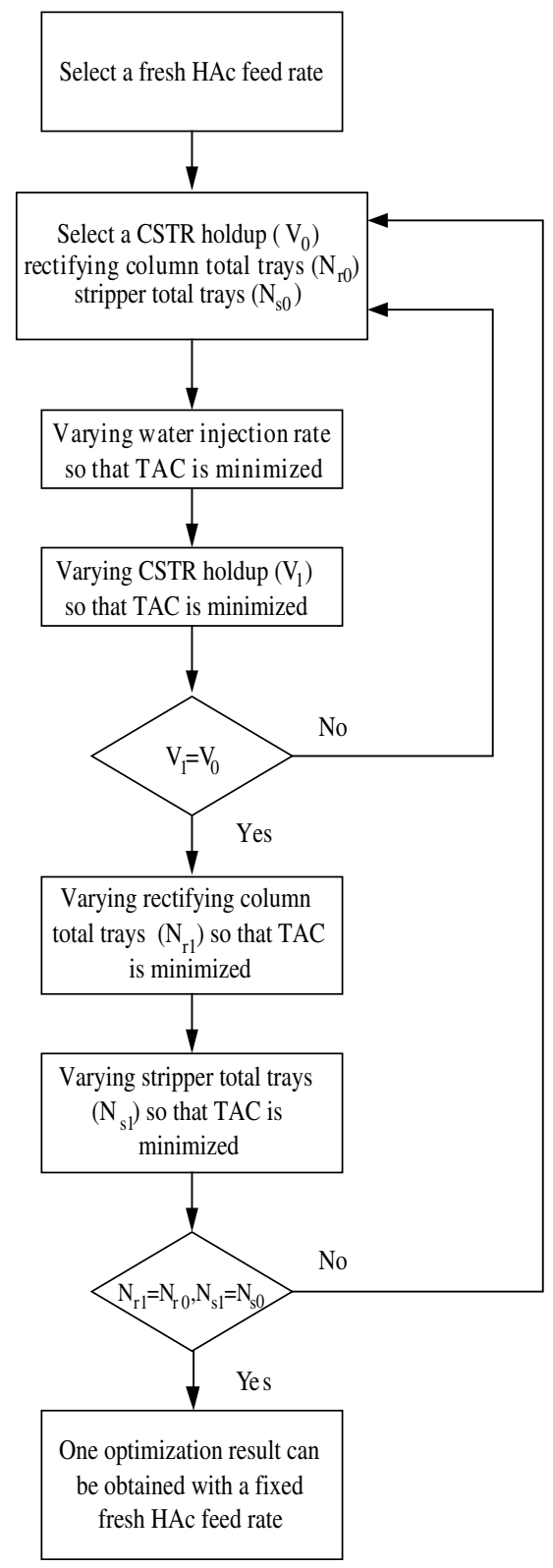

Fig. 4. The procedure of the optimization search for this system.

ough reaction holdups for this reaction. The ratio of the TAC for this coupled reactor/column system to that of the reactive distillation system in Tang et al. [7] is only 1.09. Since the proposed system in this paper has the advantage of being able to use the existing CSTR and column equipments and also other benefits mentioned in the Introduction Section, studying of this coupled reactor/column system is very valuable because only a small excess of the total annual cost needs to be spend.

Fig. 5 shows four exhaustive search runs with four given fixed fresh HAc feed rates. Each point in the figure represents full iterative search for finding the minimum TAC at this HAc feed rate. From the figure, HAc feed rate of $333 \mathrm{~g} \mathrm{~mol} / \mathrm{min}$ has been selected for the control study in the next section. This optimum feed ratio of the two reactants for this system is not set at one to one ratio as other reactive distillation papers in the literature. In this system, the optimum ratio of the pure $\mathrm{EtOH}$ to the pure HAc is 1.07:1. The extra EtOH is needed so that it can be taking out with the aqueous outlet stream (see Table 1). Notice that the pure EtOH to the pure HAc ratio is not calculated by just using the two feed flow rates since both feed streams contain some water impurity. The ideal case with almost no EtOH and no HAc in the aqueous outlet stream (this corresponds to ideally obtain the top vapor composition of rectifier at EtAc- $\mathrm{H}_{2} \mathrm{O}$ two-component azeotrope) can not be achieved unless the stages of rectifier as well as the CSTR holdup increase to unrealistic situation.

The vapor composition profiles for the two columns can be seen in Fig. 6. Notice that for the rectifier, the vapor composition for the 9th stage represents the vapor feed composition into the rectifier from the CSTR and the vapor composition for the 1st stage represents the composition of liquid stream into the decanter. The top vapor composition of the rectifier contains very little HAc to satisfy the final product impurity specification. This stream contains mostly EtAc for further purification into the final product in the stripper. Although the liquid composition profile for the rectifier is not shown in this figure, the trend is similar to the vapor composition profile with the bottom stream back into the CSTR having mostly the HAc reactant $(82.1 \mathrm{~mol} \%)$. The purpose of the stripper is to produce pure EtAc product at the column bottom. Fig. 6 clearly shows that this goal is achieved. The top vapor composition of this stripper is close to the top vapor composition of the rectifier, thus this stream is also injected into the decanter.

In order to ensure that the mixed feed composition into the decanter is well inside the two-liquid-phase boundary and at the tie-line for the desired liquid-liquid separation, additional water stream is also designed to be injected into the decanter. The purpose of the water addition is to push the mixed decanter feed composition down inside the two-liquid envelope to contain less EtOH so that after liquid-liquid separation the stripper feed stream has less EtOH. Since the HAc composition is extremely small in the stripper and also in the top vapor of the rectifier, a three-component plot of Fig. 7 can be used to demonstrate the above point.

With higher water flow rate, the organic reflux and the stripper feed composition will have less EtOH, thus resulting in easier separation and less annualized equipment cost. On the other hand, higher water flow rate will result in more EtAc loss through the aqueous stream and also more costs for the waste water treatment. Fig. 8 shows the trade-off between the annualized capital cost and the operating cost with varying water addition rate while all other design and operating variables are held at constants. Water addition rate at $600 \mathrm{gmol} /$ min is a compromise point with minimum TAC. 
Table 1

Optimum process design for this system

\begin{tabular}{|c|c|}
\hline CSTR holdup $\left(\mathrm{m}^{3}\right)$ & 90 \\
\hline Rectifier total stages (where 9th stage is the CSTR) & 9 \\
\hline Stripper total stages (including the reboiler) & 9 \\
\hline Fresh $\mathrm{EtOH}$ feed flow rate $(\mathrm{gmol} / \mathrm{min})$ & 411.9 \\
\hline EtOH feed composition & $82.2 \mathrm{~mol} \% \mathrm{EtOH}$ and $17.8 \mathrm{~mol}^{\circ} \mathrm{H}_{2} \mathrm{O}$ \\
\hline Fresh HAc feed flow rate (g mol/min) & 333.0 \\
\hline HAc feed composition & $95.2 \mathrm{~mol} \% \mathrm{HAc}$ and $4.8 \mathrm{~mol}^{\circ} \% \mathrm{H}_{2} \mathrm{O}$ \\
\hline Vapor flow rate from CSTR to rectifier ( $\mathrm{gmol} / \mathrm{min})$ & 5215 \\
\hline Bottom liquid flow rate from rectifier to $\operatorname{CSTR}(\mathrm{g} \mathrm{mol} / \mathrm{min})$ & 4470 \\
\hline Water injection rate into the decanter $(\mathrm{g} \mathrm{mol} / \mathrm{min})$ & 600.0 \\
\hline Organic reflux flow rate $(\mathrm{gmol} / \mathrm{min})$ & 3133 \\
\hline Organic outlet flow rate into stripper ( $\mathrm{g} \mathrm{mol} / \mathrm{min})$ & 1361 \\
\hline Stripper reboiler duty $(\mathrm{kW})$ & 721.7 \\
\hline Aqueous outlet flow rate $(\mathrm{g} \mathrm{mol} / \mathrm{min})$ & 1041.8 \\
\hline Aqueous outlet composition & $96.58 \mathrm{~mol}^{\circ} \% \mathrm{H}_{2} \mathrm{O}, 1.97 \mathrm{~mol}^{\%} \mathrm{EtOH}$ and $1.45 \mathrm{~mol}^{\%} \%$ EtAc \\
\hline EtAc product flow rate $(\mathrm{g} \mathrm{mol} / \mathrm{min})$ & 303.1 \\
\hline EtAc product composition & $\begin{array}{l}99.58 \mathrm{~mol}^{\circ} \% \text { EtAc, } 0.015 \mathrm{~mol}^{\circ} \%\left(0.010 \mathrm{wt}^{\%} \%\right) \mathrm{HAc}, 0.38 \mathrm{~mol}^{\circ} \%\left(0.20 \mathrm{wt}^{\circ} \%\right) \mathrm{EtOH} \\
\text { and } 0.025 \mathrm{~mol}^{\circ} \mathrm{H}_{2} \mathrm{O}\end{array}$ \\
\hline
\end{tabular}

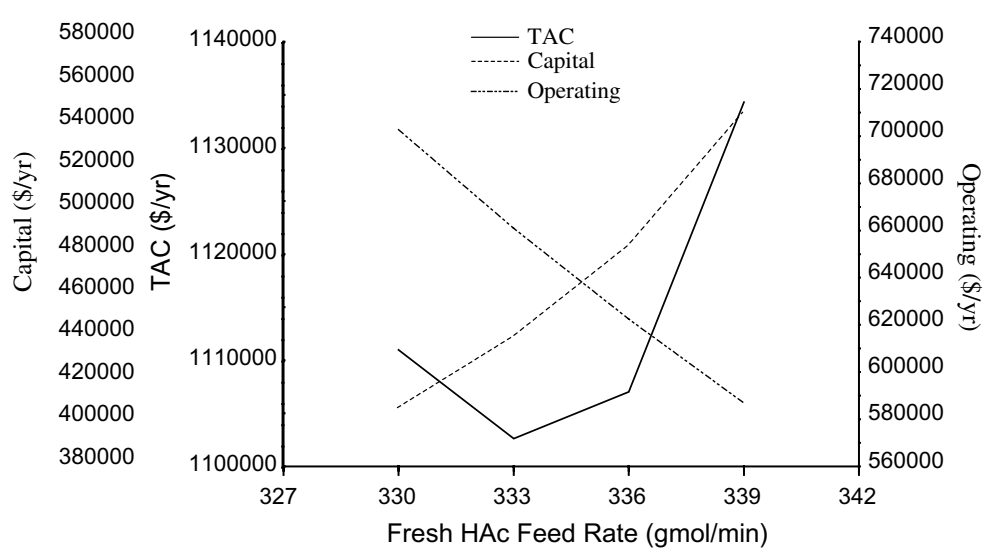

Fig. 5. Minimized TAC at each fixed HAc feed flow rate.

For the CSTR holdup, larger holdup promotes more reaction thus less operating cost (e.g., heat duty) is needed for the product purification. On the other hand, larger CSTR holdup means more annualized equipment cost for the reactor. Fig. 9 shows the trade-off between the annualized capital cost and the operating cost with varying CSTR holdup while all other design and operating variables are held at constants. Notice that for the CSTR holdup at $86-88 \mathrm{~m}^{3}$, the trend for the increasing of capital cost with increasing CSTR holdup is actually reversed. This is because in these situations, the reductions of column diameters play more important role in the overall capital cost than the increasing of the CSTR holdup. The compromise point for the minimum TAC is at the CSTR holdup of $90 \mathrm{~m}^{3}$.

\section{Control strategy development}

After the optimum steady-state base case condition has been established, the next step is to convert this stea- dy-state simulation into dynamic simulation. Aspen Dynamics ${ }^{\mathrm{TM}}$ will be used to evaluate dynamic response of the proposed control strategy under feed flow rate and feed composition disturbances.

The disturbances considered for evaluation purpose include: $\pm 20 \%$ changes in the base flow (fresh EtOH flow) of the system, $\pm 20 \%$ changes in the $\mathrm{EtOH}$ feed $\mathrm{H}_{2} \mathrm{O}$ composition, and $\pm 50 \%$ changes in the HAc feed $\mathrm{H}_{2} \mathrm{O}$ composition. Notice that both feeds contain some $\mathrm{H}_{2} \mathrm{O}$ in the feed streams with normal EtOH feed composition having $17.8 \mathrm{~mol} \%$ of $\mathrm{H}_{2} \mathrm{O}$ and normal $\mathrm{HAc}$ feed composition having $4.8 \mathrm{~mol}^{\%}$ of $\mathrm{H}_{2} \mathrm{O}$. These base case feed compositions are taken from Alejski and Duprat [3].

\subsection{Inventory control loops}

The inventory control loops of this overall system need to be determined first and then the product quality control loops can be designed. Sometimes this is an iterative control design procedure because we can swap the 

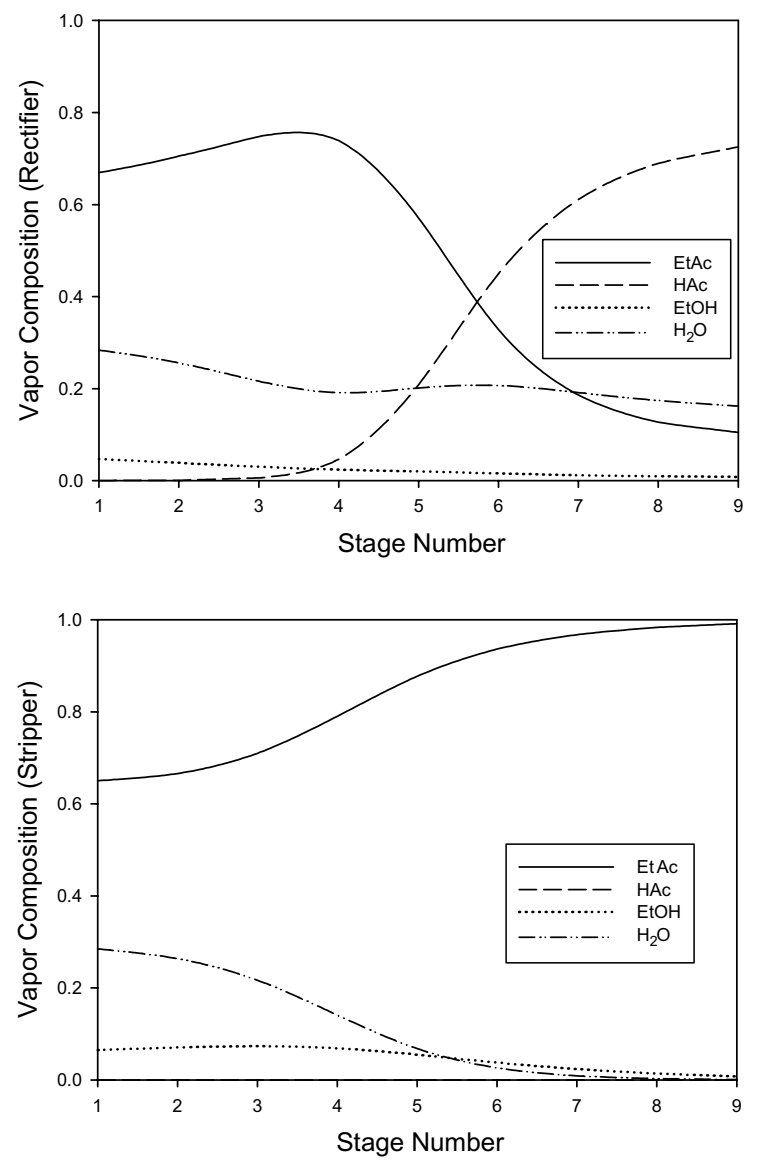

Fig. 6. The vapor composition profiles for the two columns.

manipulated variables in the inventory loops with that of the product quality control loops. The organic phase level of the decanter will be controlled by manipulating the organic outlet flow which is also the feed flow to the stripper. The aqueous phase level of the decanter will be controlled by manipulating the aqueous outlet flow. The bottom level of the stripper will be controlled by manipulating the bottom flow which is also the final product flow. P-only controllers as suggested in Luyben [14] are used for these three level loops. The reason for the P-only control is because maximum flow smoothing can be obtained for this recycled process. The small level offset introduced by the P-only controller will not affect the final steady-state result. On the contrary, if PI controllers are used for the level loops, additional oscillation introduced by the I-mode of the controller may be exhibited to slow down the settling time of this recycled process.

Pressures at top of two columns are all controlled by their vapor outlet flows. The remaining inventory control loop is the CSTR level loop. This is a very important inventory control loop because this level determines the reaction volume. The dynamic response of other inventory loops will not affect the final steady-state result but this loop will, thus PI controller is used in this CSTR level loop to ensure no offset of this level control loop. Since the liquid bottom flow rate of the CSTR is set at zero, other alternative manipulated variables should be considered to control the CSTR level. The candidate alternative manipulated variables are: the CSTR heat duty, the fresh HAc feed flow rate, and the organic reflux flow. The fresh HAc feed flow is rejected in the consideration because this flow rate is relatively much lower in comparison with the other flow rates in/out of the CSTR (see Table 1). The organic reflux flow is also rejected in the consideration because it is dynamically deficient. It needs to travel from the top of the rectifier to the bottom into CSTR. The only manipulated variable left which is suitable to control the

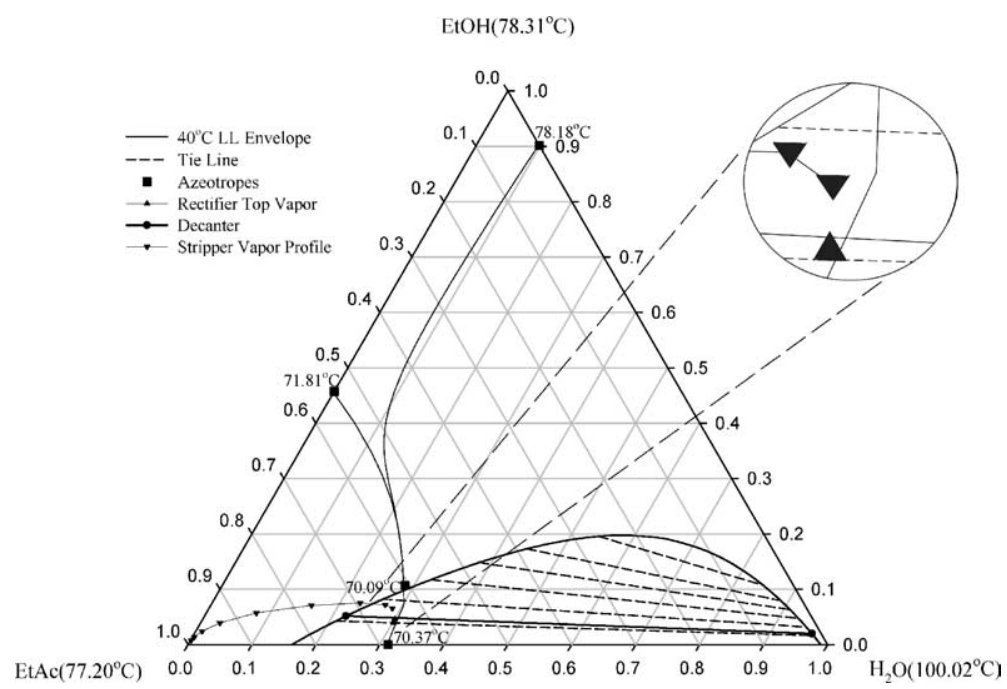

Fig. 7. Three-component plot for the rectifier top vapor, the decanter, and the stripper profile. 


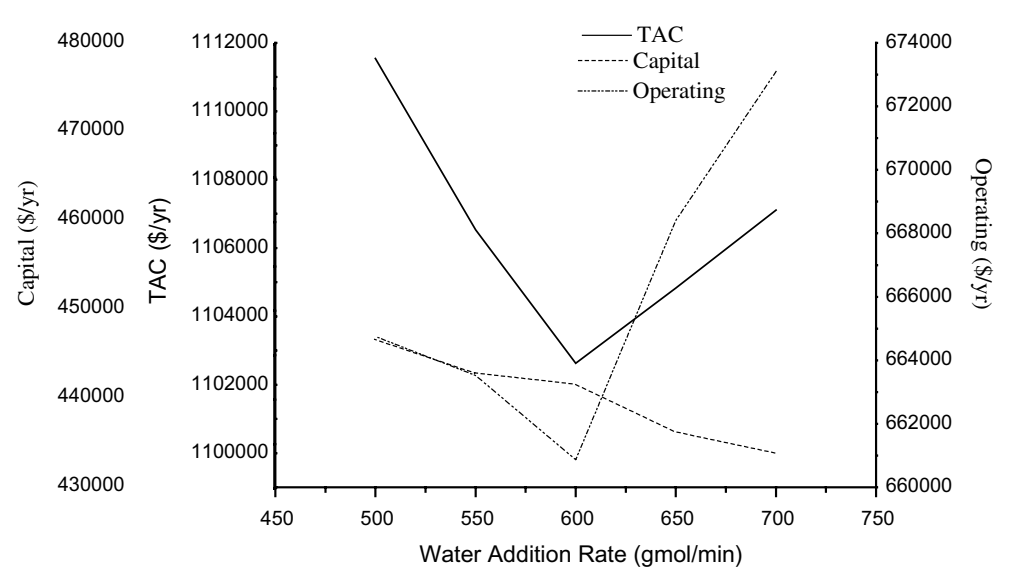

Fig. 8. Effect of water addition rate on TAC.

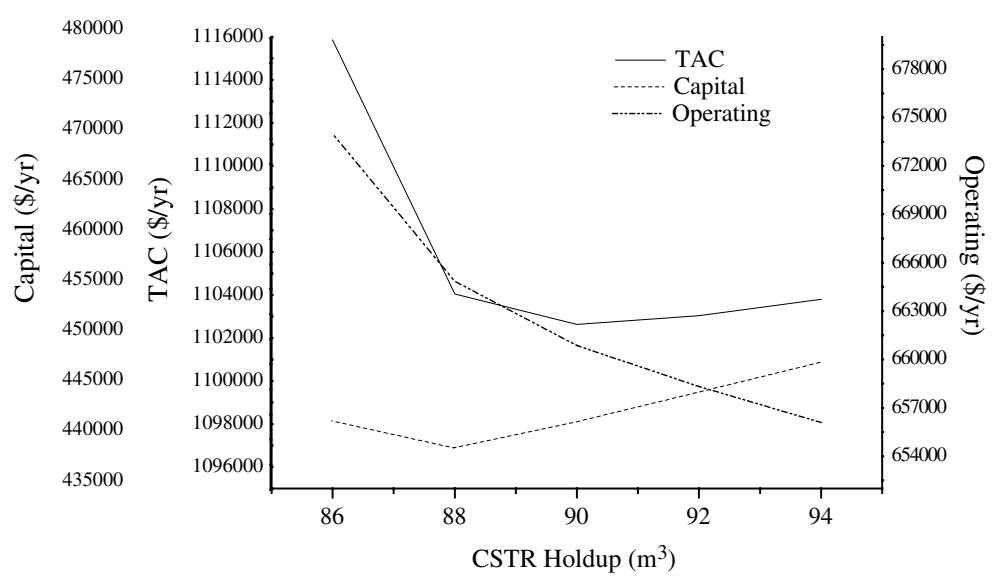

Fig. 9. Effect of the CSTR holdup on TAC.

CSTR level is the CSTR heat duty. This manipulated variable will affect the vapor flow leaving the CSTR thus changing the CSTR level.

After deciding the overall inventory control loops, the remaining manipulated variables which can be used in product purity control loops are: the fresh HAc feed flow, the organic reflux flow, the water injection rate, and the reboiler duty of the stripper. Ratio schemes will be implemented to allow for some feedforward compensation for the measurable disturbances. The fresh HAc feed flow rate will be ratio to the base flow rate of EtOH. The water injection rate will also be ratio to the base flow rate of EtOH. These two ratios are set according to the base case condition in Table 1. The organic reflux flow rate will be ratio to the organic outlet flow rate so that organic reflux ratio is held at a constant value as the base case condition.

\subsection{Selection of the temperature control point}

Only tray temperature measurements will be considered for inferential control of the final product purity.
The assumption of no available on-line composition measurement agrees well with the real industrial situation. In order to determine the proper temperature control point(s), sensitivity analysis will be performed next to determine the temperature control point(s). Some tray temperature in the rectifier will be used to infer the HAc impurity in the final EtAc product stream. This is workable because any HAc impurity in the top vapor stream of the rectifier will be proportionally shown in the final EtAc product stream. Certain tray temperature in the stripper will be used to infer the EtOH impurity in the final EtAc product stream. The sensitivity analysis at the rectifier can be seen in the following Figs. 10 and 11 for $\pm 1 \%$ changes in the fresh HAc feed ratio and $\pm 1 \%$ changes in the organic reflux ratio, respectively.

The first observation from these two figures of sensitivity analysis is that the fresh HAc feed ratio has the strongest effect to the tray temperatures. Only small $\pm 1 \%$ changes in the fresh HAc feed ratio causes large changes to the tray temperatures in the rectifier. For comparison, the effect due to $\pm 1 \%$ changes in the organic reflux ratio is much smaller than $\pm 1 \%$ changes in the 


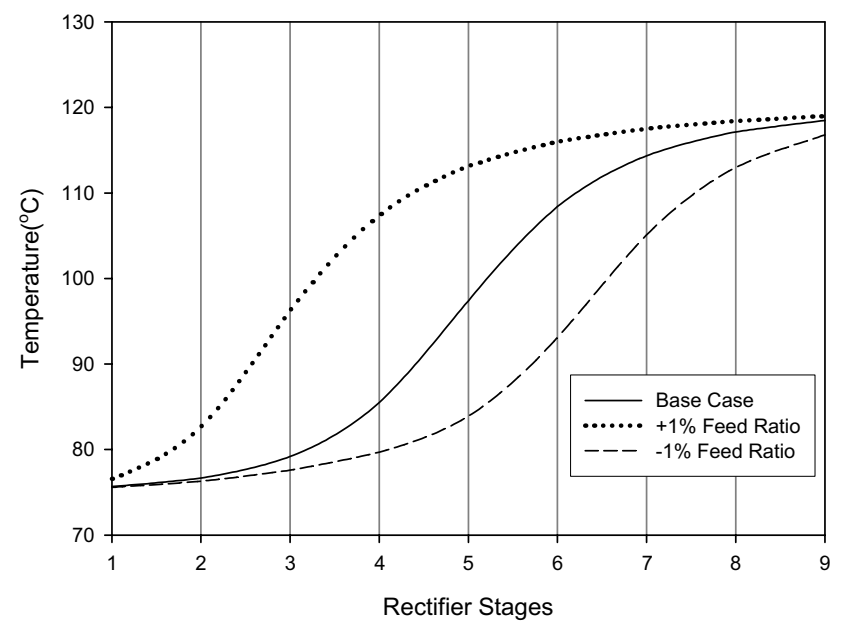

Fig. 10. $\pm 1 \%$ changes in the fresh HAc feed ratio on temperature at each stage.

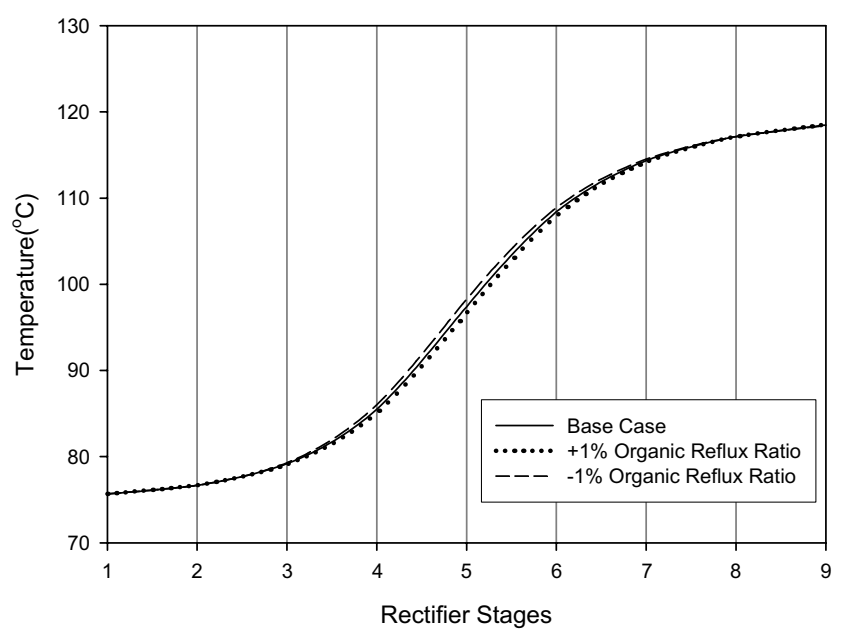

Fig. $11 . \pm 1 \%$ changes in the organic reflux ratio on temperature at each stage.

fresh HAc feed ratio. It is concluded that the fresh HAc feed ratio should be used to control some stage temperature inside the rectifying column. The 5th stage temperature will be used as the control point because the sensitivity is large and also the behavior is quite linear. This quite linear behavior can be observed in Fig. 10 by calculating the process gains for $\pm 1 \%$ changes in the fresh HAc feed ratio. Fig. 12 shows the HAc vapor composition profiles for $\pm 1 \%$ changes in the fresh HAc feed ratio. Notice that at the 5th stage the HAc vapor composition also varies significantly for $\pm 1 \%$ changes in the fresh HAc feed ratio. The sensitivity of composition and temperature corresponds well at the 5th stage. The sensitivity analysis at the stripper can be seen in Fig. 13 for $\pm 10 \%$ changes in the reboiler duty. From the figure, the 5 th stage temperature should be used as the control point by manipulating the reboiler duty.

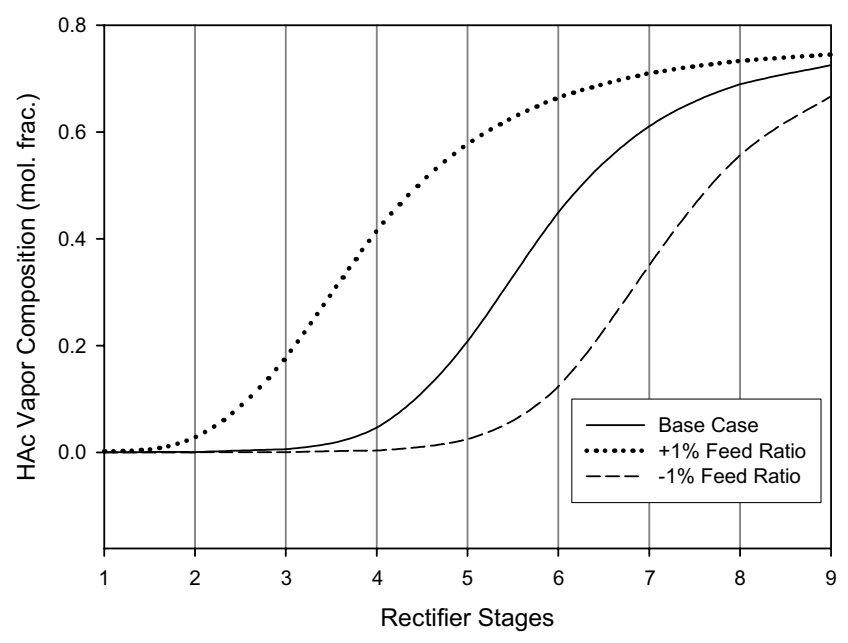

Fig. 12. $\pm 1 \%$ changes in the fresh HAc feed ratio on HAc vapor composition at each stage.

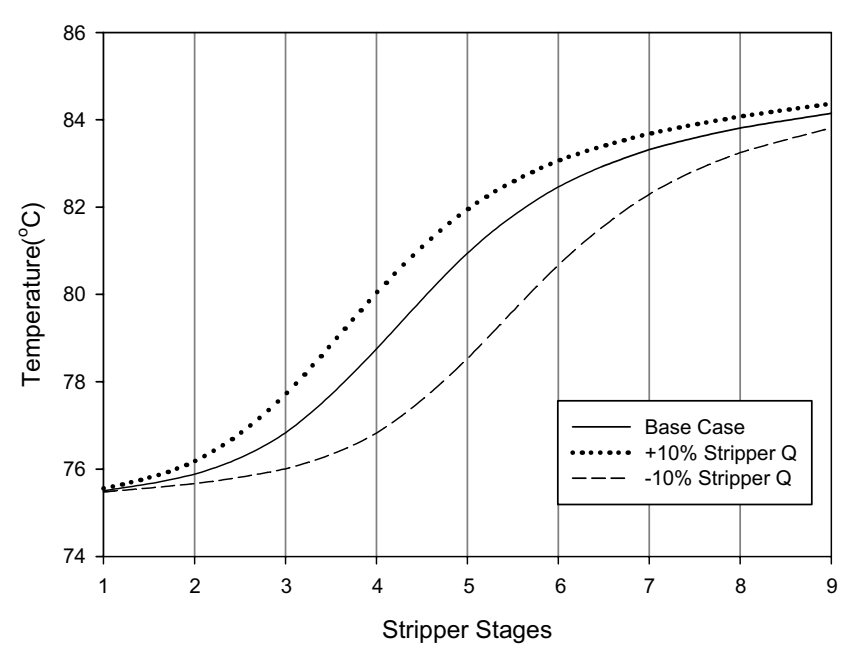

Fig. 13. $\pm 10 \%$ changes in the reboiler duty of the stripper on temperature at each stage.

\subsection{Tuning of the two temperature control loops}

The proposed overall control strategy is presented in Fig. 14. Notice that the ratio schemes are implemented for the un-used organic reflux flow to maintain a constant organic reflux ratio. The water injection rate is also varied in accordance with the base EtOH feed flow rate. The IMC-PI tuning rules of Chien and Fruehauf [15] will be used to determine the PI tuning parameters of the two important temperature loops which infer the final product composition.

The initial dynamic responses of the open-loop step changes will be use to tune these two temperature loops. Fig. 15 shows the open-loop step response of the rectifier 5th stage temperature with $\pm 1 \%$ changes in the fresh HAc feed ratio at time $=1 \mathrm{~h}$. Only the first two hours initial dynamic responses are used to calculate the model 


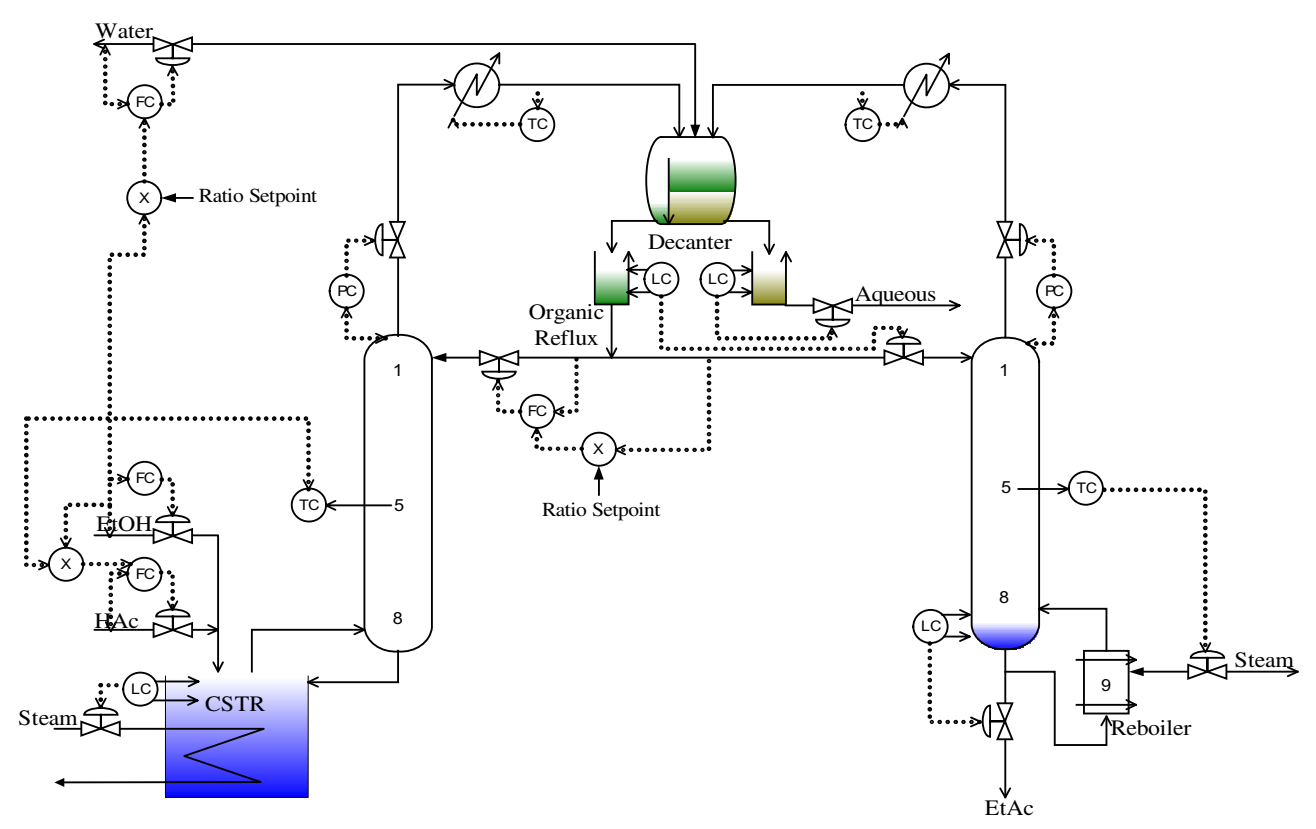

Fig. 14. Proposed overall control strategy of this system.

parameters of an integrating model with deadtime. The dynamic responses with these small perturbations are observed to be quite linear because symmetrical dynamic behavior is observed in this figure. Once the model parameters are obtained from the step test, the PI tuning parameters can easily be calculated following Chien and Fruehauf [15]. The closed-loop tuning parameter, $\tau_{\mathrm{cl}}$, is set to be twice of the apparent deadtime of this system. The PI tuning constants used in the closed-loop simulations are: $K_{\mathrm{c}}=15.9$ and $\tau_{\mathrm{I}}=48$ min.

Fig. 16 shows the open-loop step response of the stripper 5 th stage temperature with $\pm 1 \%$ changes in the reboiler duty at time $=1 \mathrm{~h}$. Notice that the dynamic

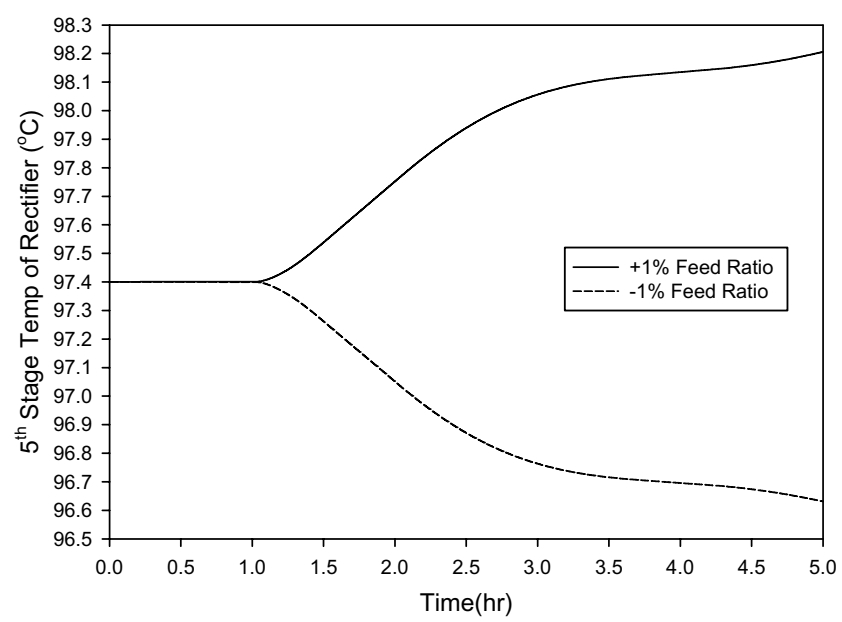

Fig. 15. Open-loop initial dynamic response for $\pm 1 \%$ changes in the fresh HAc feed ratio. response is very unusual. Large overshoots are observed in this open-loop step test. The overshoot response is mainly due to the plantwide arrangement of this recycle process. The feed flow rate and its compositions are changed considerably due to the recycle stream of the stripper top vapor. The overshoot response is due to the composite dynamic response of the changes in the reboiler duty, feed flow rate, and the feed composition. Again, the initial dynamic response is most important for the controller tuning purpose. Only the initial dynamic response (uses first $30 \mathrm{~min}$ to determine the model parameters) is actually due to the changes in the reboiler duty alone, thus this part of the dynamic response is used for controller tuning purpose. Again, this system

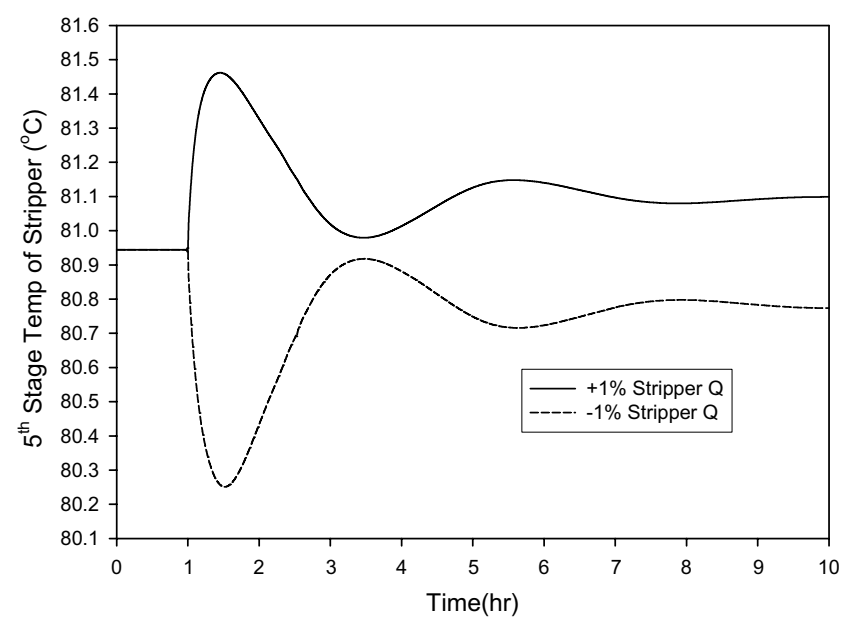

Fig. 16. Open-loop initial dynamic response for $\pm 1 \%$ changes in the reboiler duty of the stripper. 
is modeled as an integrating process to obtain the PI tuning parameters. The PI tuning constants for this loop are: $K_{\mathrm{c}}=6.28$ and $\tau_{\mathrm{I}}=20 \mathrm{~min}$. One thing needs to be mentioned is that this tuning strategy of emphasizing the initial dynamic response needs to be modified when encounters inverse-response system. In this case, the time duration for the initial inverse response will be treated as additional deadtime in the process model for controller tuning purpose.

\subsection{Closed-loop simulation results}

The closed-loop response for $\pm 20 \%$ EtOH feed flow rate changes can be seen in Fig. 17. The disturbances are introduced at time $=5 \mathrm{~h}$. Notice that both tempera-
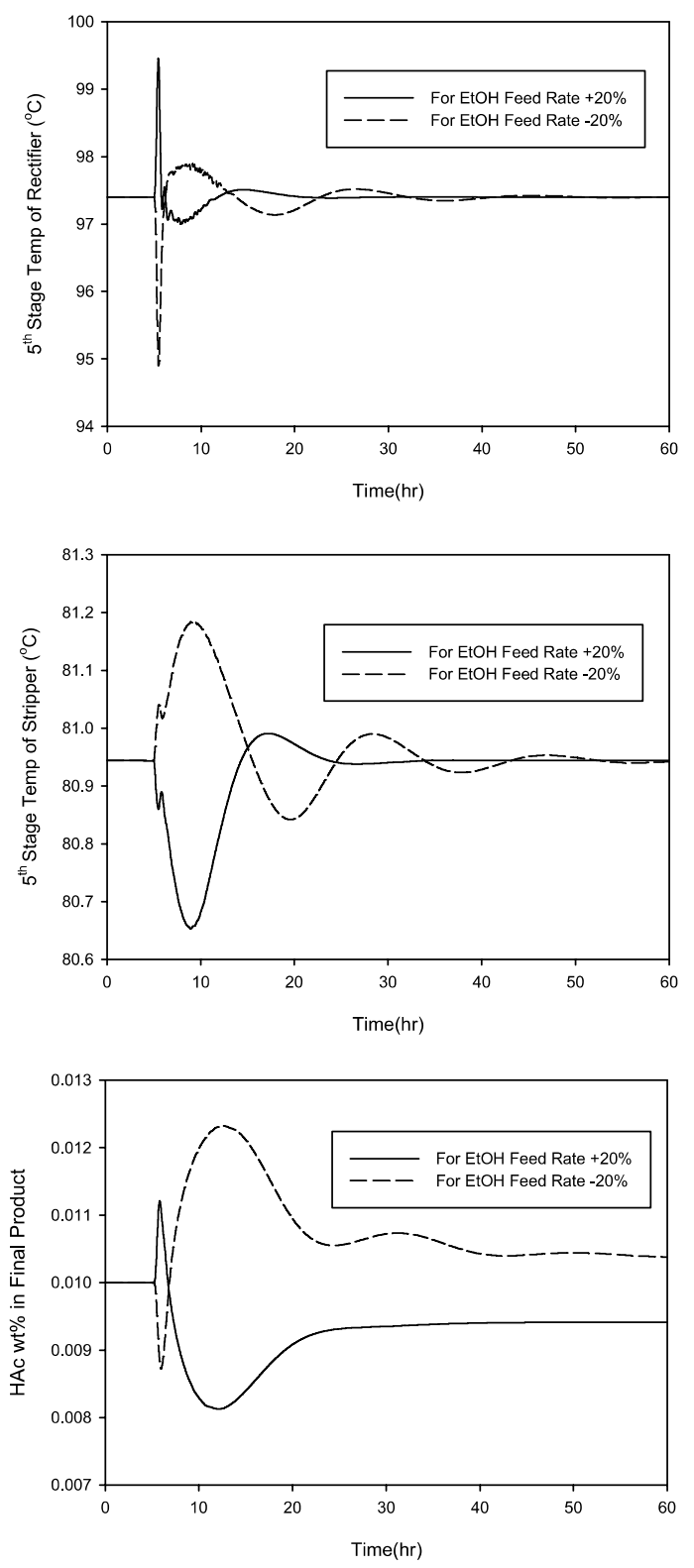

ture control points are controlled back to their setpoint values quite nicely. The manipulated variables are also moved quite smoothly with no abrupt changes. Although the closed-loop time constants appear to be rather large, however, for this industrial scaled process, this smooth closed-loop dynamic behavior is quite acceptable in industry. The HAc to EtOH feed ratio is actually return back to original ratio after some transient response. The dynamic response of the HAc and EtOH impurities in the final product stream can also be seen in this figure (bottom two plots). Since there is no direct composition control loop in this proposed control scheme due to lack of on-line composition analyzer, small deviation of the impurity from the base case condition is inevitable. For these stringent product impurity specifications, the final
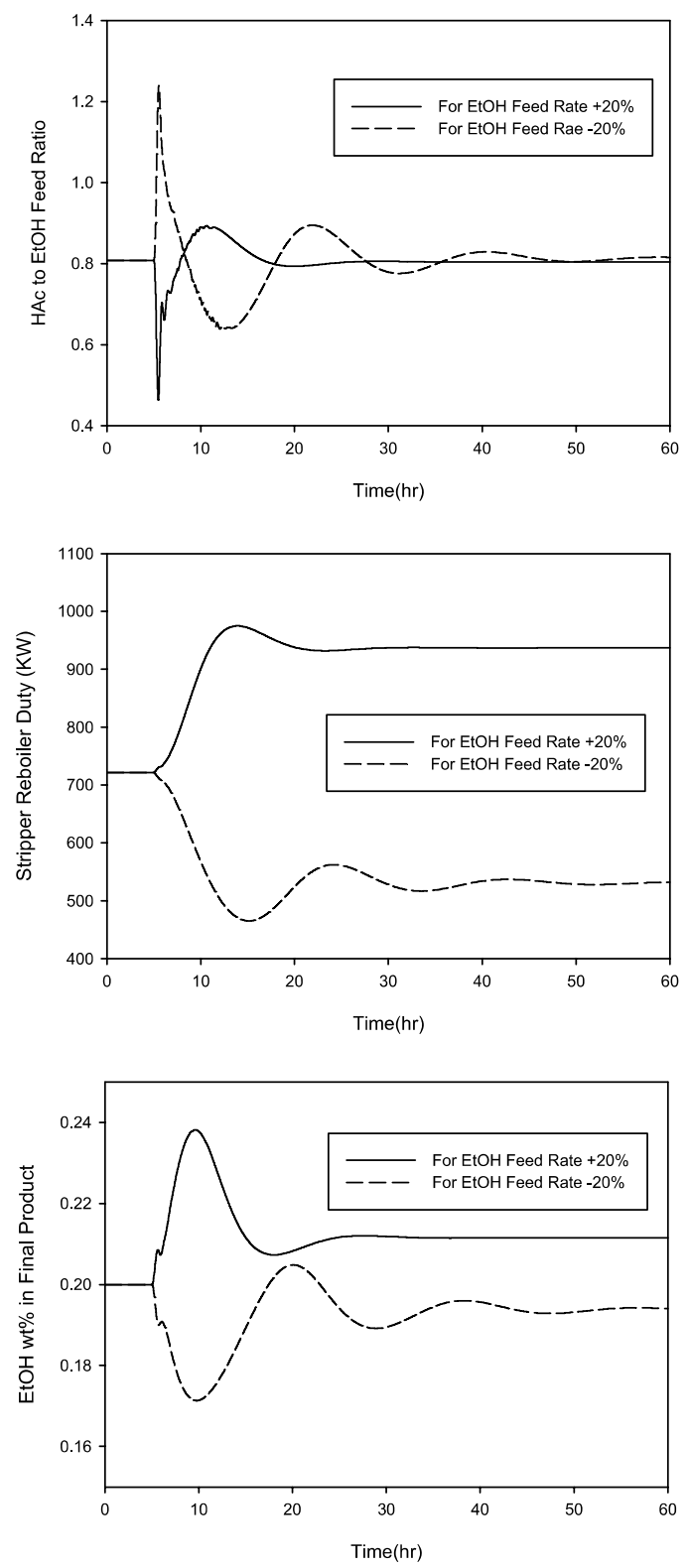

Fig. 17. Closed-loop dynamic response for $\pm 20 \%$ changes in the fresh EtOH feed flow rate. 
deviations of the two product impurities are considered to be quite small and satisfactory.

The above disturbance test can be viewed as how good the overall control strategy performed with throughput demand changes. Notice that the EtOH feed flow rate is assumed to be measurable, thus ratio schemes in this proposed control strategy are in action to cope with this load change. The next two disturbance tests are unmeasured load changes. $\pm 20 \%$ changes in the EtOH feed $\mathrm{H}_{2} \mathrm{O}$ composition and $\pm 50 \%$ changes in the $\mathrm{HAc}$ feed $\mathrm{H}_{2} \mathrm{O}$ composition will be introduced into this system. The crucial evaluation is to show if the product impurity specifications can also be approximately maintained. Fig. 18 shows the closed-loop dynamic response for $\pm 20 \%$ changes in the EtOH feed $\mathrm{H}_{2} \mathrm{O}$ composition.
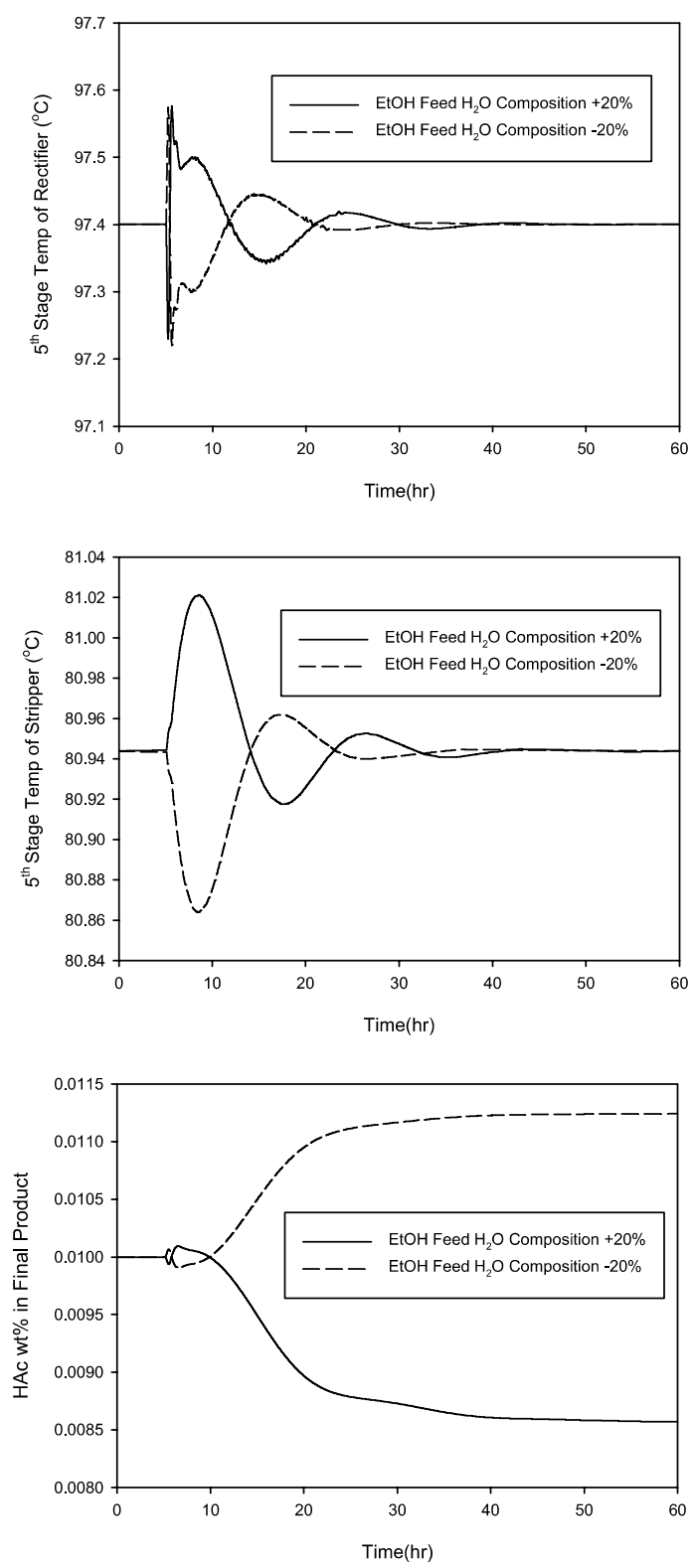

Again, both temperature control points are controlled back to their setpoint values quite nicely. In this case, the HAc to EtOH feed ratio is changed to cope with this unmeasured feed composition disturbance. The HAc impurity in the product stream has more final steadystate deviation from the specification. The HAc impurity is going up to $0.0113 \mathrm{wt} \%$ for $-20 \%$ changes in the EtOH feed $\mathrm{H}_{2} \mathrm{O}$ composition.

The closed-loop dynamic response for the $\pm 50 \%$ changes in the $\mathrm{HAc}$ feed $\mathrm{H}_{2} \mathrm{O}$ composition is shown in Fig. 19. From the figure, it is observed that the impact of this unmeasured load disturbance to the system is smaller than the previous one in Fig. 18. Both temperature control points and the final product impurities are all behaved nicely.
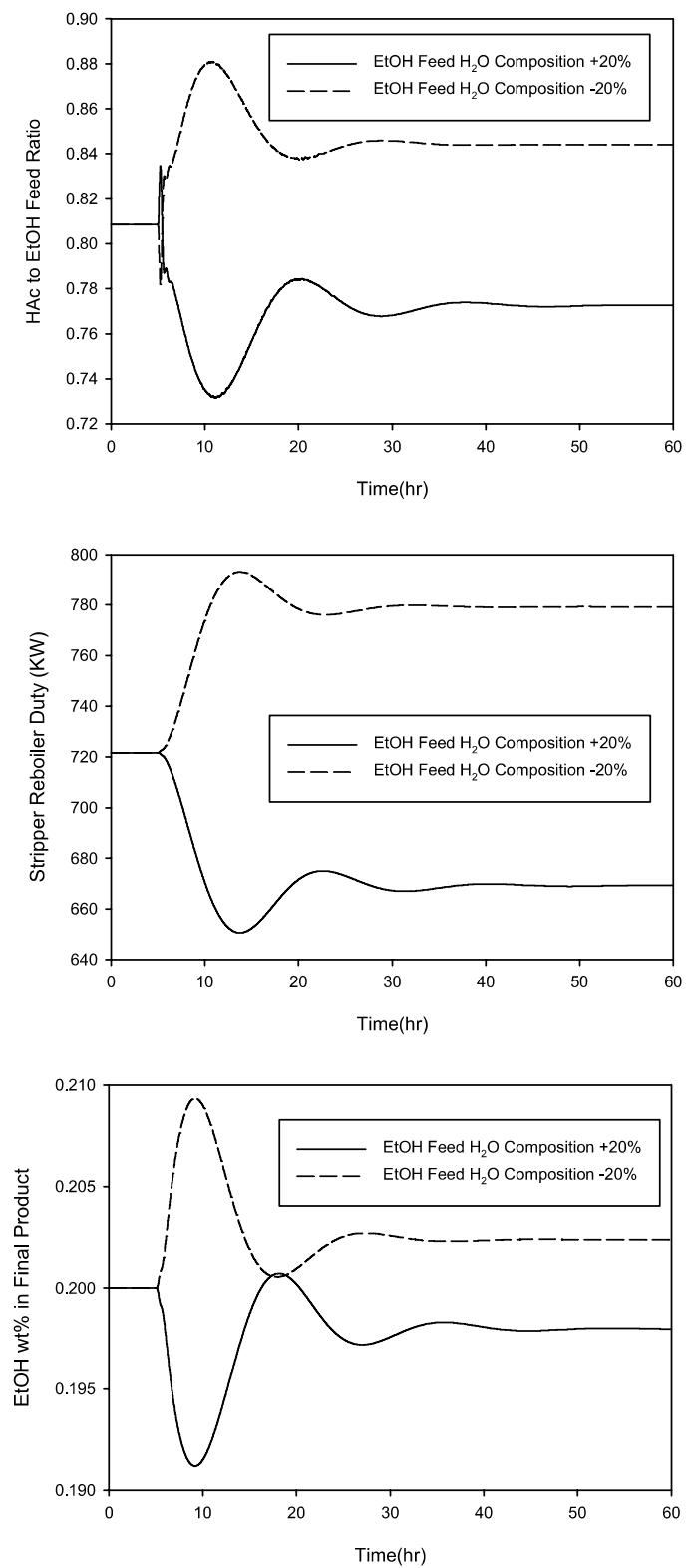

Fig. 18. Closed-loop dynamic response for $\pm 20 \%$ changes in the EtOH feed $\mathrm{H}_{2} \mathrm{O}$ composition. 

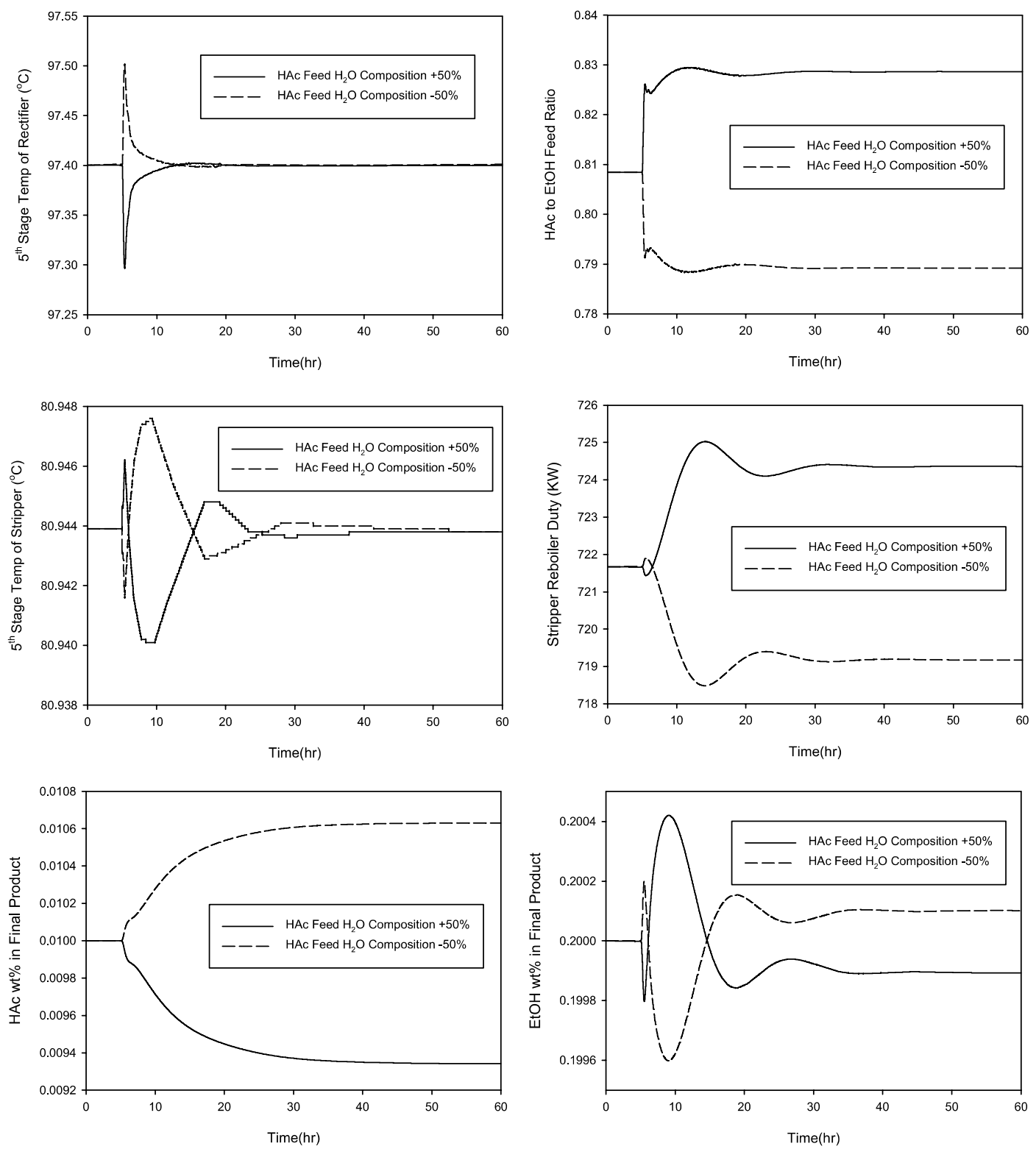

Fig. 19. Closed-loop dynamic response for $\pm 50 \%$ changes in the $\mathrm{HAc}$ feed $\mathrm{H}_{2} \mathrm{O}$ composition.

Since $-20 \%$ changes in the EtOH feed $\mathrm{H}_{2} \mathrm{O}$ composition causes the most steady-state deviation of the HAc impurity specification in the above study, a practical method is demonstrated next to bring the HAc impurity back to specification. Assumed that every few hours the product impurity composition can be measured off-line from the quality lab of this plant, thus one can change the temperature setpoints to bring the impurity back to specification. Fig. 20 shows the closed-loop dynamic response for such situation. At time $=5 \mathrm{~h},-20 \%$ changes in the EtOH feed $\mathrm{H}_{2} \mathrm{O}$ composition is introduced into the system, some final deviation for the HAc impurity in the product stream is shown just like previous Fig. 18. At time $=50 \mathrm{~h}$, the temperature setpoint value for the loop at rectifier is changed from 97.4 to $96.6{ }^{\circ} \mathrm{C}$. The closed-loop servo response of the controlled temper- ature is very fast in reaching the new setpoint value. More importantly, the HAc impurity is back to around the specification value from 0.0113 to $0.010 \mathrm{wt} \%$ after the setpoint change. At time $=100 \mathrm{~h}$, a small change of the setpoint value for the temperature control loop at stripper is made. The setpoint value is changed from 80.94 to 80.97 ${ }^{\circ} \mathrm{C}$. Notice from the $\mathrm{EtOH}$ product impurity dynamic response, this impurity is changed from 0.202 to $0.200 \mathrm{wt} \%$ which is back to original specification. This small change in the temperature setpoint value may not be realistic and also may not be necessary since the EtOH impurity is very close to the specification. The reason to include the simulation run from time $=100$ to $150 \mathrm{~h}$ is to show that there is a decoupling effect on the two product impurity specifications. Changing the temperature setpoint value for the loop at rectifier will affect the HAc impurity but not on 

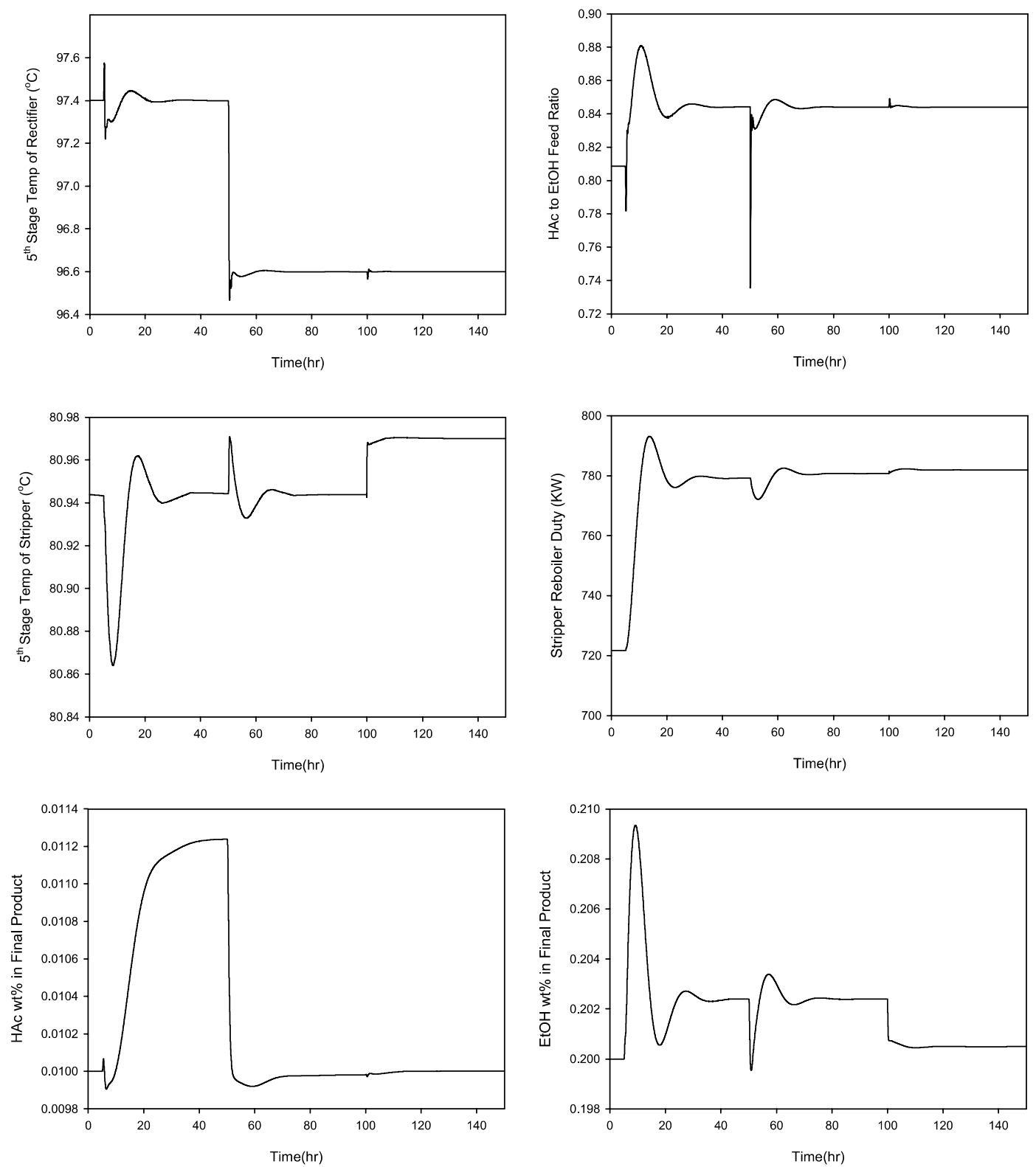

Fig. 20. Closed-loop dynamic response to demonstrate the slow off-line cascade control. @ time $=5 \mathrm{~h},-20 \%$ change in the EtOH feed $\mathrm{H}_{2} \mathrm{O}$ composition is made, @ time=50 h, the temperature setpoint for the control loop at rectifier is changed from 97.4 to $96.6^{\circ} \mathrm{C}$, @ time=100 h, the temperature setpoint for the control loop at stripper is changed from 80.94 to $80.97{ }^{\circ} \mathrm{C}$.

the EtOH impurity. Similarly, changing the temperature setpoint value for the loop at stripper will affect the EtOH impurity but not altering the HAc impurity much at all. This decoupling nature is most desirable, since one can immediately decide to change the setpoint value of which temperature loop to adjust the final product impurity.

\section{Conclusions}

Design and control of a realistic industrial scaled coupled reactor/column process to produce ethyl ace- tate is studied in this paper. The design of this system needs to be more complicated than the other coupled reactor/column systems in the literature. Search procedure is developed to obtain the optimum process design and operating condition of this process. The optimum process design is the one that minimize the Total Annual Cost (TAC) of this process. The optimum overall process design includes a continuous-stirred tank reactor (CSTR) coupled with a rectifier, a decanter, another stripper, and a recycle stream. The design and operating variables in this search procedure are: the CSTR holdup, the total number of stages for the rectifier, the total number of stages for the stripper, the fresh 
HAc feed flow rate, and the water injection rate. The overall control strategy of this system is also developed. The recommended control strategy uses the ratio of acetic acid feed rate to ethanol feed rate to control the 5th stage temperature of the rectifier and uses the stripper reboiler duty to control the 5th stage temperature of the stripper. This simple control strategy does not need any on-line composition measurements. The stringent product impurity specifications of $0.01 \mathrm{wt} \%$ $\mathrm{HAc}$ and $0.2 \mathrm{wt} \% \mathrm{EtOH}$ in the EtAc product stream can properly be held despite feed flow rate and also feed composition disturbances. A slow cascade outer composition loop structure can also be implemented using off-line composition measurements from the quality lab. This control structure has been demonstrated to be successful in eliminating small deviation of the product impurity compositions to their specifications.

\section{Acknowledgment}

This work is supported by the National Science Council of the ROC under Grant No.: NSC 91-2214E-011-012.

\section{References}

[1] Y.A. Chang, J.D. Seader, Simulation of continuous reactive distillation by a homotopy-continuation method, Comput. Chem. Eng. 12 (1988) 1243-1255.
[2] J. Simandl, W.Y. Svrcek, Extension of the simultaneous-solution and inside-outside algorithms to distillation with chemical reactions, Comput. Chem. Eng. 15 (1991) 337-348.

[3] K. Alejski, F. Duprat, Dynamic simulation of the multicomponent reactive distillation, Chem. Eng. Sci. 51 (1996) 4237-4252.

[4] D.B. Keyes, Esterification processes and equipment, Ind. Eng. Chem. 24 (1932) 1096-1103.

[5] H. Bock, M. Jimoh, G. Wozny, Analysis of reactive distillation using the esterification of acetic acid as an example, Chem. Eng. Technol. 20 (1997) 182-191.

[6] N. Vora, P. Daoutidis, Dynamic and control of an ethyl acetate reactive distillation column, Ind. Eng. Chem. Res. 40 (2001) 833-849.

[7] Y.T. Tang, H.P. Huang, I.L. Chien, Design of a complete ethyl acetate reactive distillation system, J. Chem. Eng. Japan 36 (2003) 1352-1363.

[8] C.K. Yi, W.L. Luyben, Design and control of coupled reactor/ column systems - Part 1. A binary coupled reactor/rectifier system, Comput. Chem. Eng. 21 (1997) 25-46.

[9] C.K. Yi, W.L. Luyben, Design and control of coupled reactor/ column systems - Part 2. more complex coupled reactor/column system, Comput. Chem. Eng. 21 (1997) 47-67.

[10] C.K. Yi, W.L. Luyben, Design and control of coupled reactor/ column systems - Part 3. a reactor/stripper with two columns and recycle, Comput. Chem. Eng. 21 (1997) 69-86.

[11] S.F. Chiang, C.L. Kuo, C.C. Yu, D.S.H. Wong, Design alternatives for the amyl acetate process: coupled reactor/column and reactive distillation, Ind. Eng. Chem. Res 41 (2002) 3233-3246.

[12] R.J. Burkett, D. Rossiter;, Choosing the right control stucture for industrial distillation columns, Proc. Process Control Instrument. (2000) 38-42.

[13] J.G. Hayden, J.P. O'Connell, A generalized method for predicting second virial coefficients, Ind. Eng. Chem. Process Des. Dev. 14 (1975) 209-216.

[14] W.L. Luyben, Plantwide Dynamic Simulators in Chemical Processing and Control, Marcel Dekker, Inc., New York, 2002.

[15] I.L. Chien, P.S. Fruehauf, Consider IMC tuning to improve controller performance, Chem. Eng. Prog. 86 (1990) 33-41. 